\section{International Scientific Journal Theoretical \& Applied Science}

\author{
p-ISSN: 2308-4944 (print) e-ISSN: 2409-0085 (online) \\ Year: $2016 \quad$ Issue: 3 Volume: 35 \\ Published: $30.03 .2016 \quad$ http://T-Science.org
}

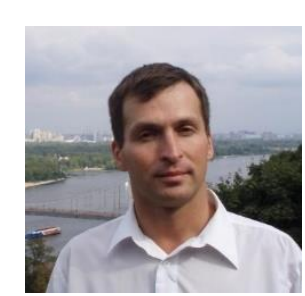

Maxim Ruslanovich Moskalenko

Associate Professor, Ph.D.

Ural Federal University named after the first President of Russia

Boris Yeltsin (UrFU) max.rus.76@mail.ru

SECTION 17. World History. History of Science and Technology.

\title{
ABOUT THE CONCEPT OF TEACHING OF THE DISCIPLINE «THE HISTORY OF SCIENCE AND TECHNOLOGY» IN LEVELED VOCATIONAL EDUCATION
}

Abstract: This paper considers questions teaching of the discipline "History of Science and Technology" in the modern leveled professional education. Determines the main tasks of this course for the formation of competencies of future professionals. We study the main points of this course which are of interest for students and for researchers.

Key words: history of science and technology, leveled vocational education.

Language: Russian

Citation: Moskalenko MR (2016) ABOUT THE CONCEPT OF TEACHING OF THE DISCIPLINE «THE HISTORY OF SCIENCE AND TECHNOLOGY» IN LEVELED VOCATIONAL EDUCATION. ISJ Theoretical \& Applied Science, 03 (35): 26-31.

Soi: http://s-o-i.org/1.1/TAS-03-35-5 Doi: crossef http://dx.doi.org/10.15863/TAS.2016.03.35.5

\section{О КОНЦЕПЦИИ ПРЕПОДАВАНИЯ УЧЕБНОЙ ДИСЦИПЛИНЫ «ИСТОРИЯ НАУКИ И ТЕХНИКИ» В УРОВНЕВОМ ПРОФЕССИОНАЛЬНОМ ОБРАЗОВАНИИ}

\begin{abstract}
Аннотация: В данной работе рассматриваются вопросы преподавания учебной дисцииллны «История науки и техники» в современном уровневом профессиональном образовании. Определяются основные задачи данного курса для формирования компетенций будущих профессионалов. Изучаются ключевые моменты данного учебного курса, представляющие интерес как для учащихся, так и для исследователей.
\end{abstract}

Ключевые слова: история науки и техники, уровневое профессиональное образование.

Введение. Современное уровневое профессиональное образование ставит своей задачей подгосовку квалифицированного работника соответствующего уровня (бакалавра, специалиста, магистра) - компетентного, свободно владеющего собственной профессией и ориентирующегося в смежных профессиональных областях. Целью подготовки выпускника в вузе является формирование специалиста, готового качественно и творчески осуществлять обозначенные профессиональной деятельностью функции за минимальные адаптационные сроки [1, с. 48]. И здесь большое значение имеют вспомогательные учебные дисциплины, которые способствуют развитию эрудиции студента, культуры научного мышления и решения научных проблем, представления о ключевых вопросах современных естественных и гуманитарных наук.
В этом плане очень высока роль такой учебной дисциплины, как «История науки и техники» (читаемой в ряде вузов Российской Федерации), которая синтезирует задачи учебных дисциплин естественнонаучного и гуманитарного планов. Она призвана развивать у учащихся необходимый кругозор по самым различным областям научно-технического развития общества, формировать культуру научного мышления, давать примеры деятельности изобретателей, знакомить с их алгоритмами решения исследовательских задач и т.д. [2, с. 242]. Отметим, что в ведущих западных вузах преподаванию истории науки и техники отводится очень большое значение [3].

Основные вопросы курса. В советской индустриальной цивилизации существовал идеал широко эрудированного специалистаинтеллектуала. В основе данного идеала лежала 
энциклопедическая наука Нового времени. Ученые-энциклопедисты эпохи Просвещения были официально признаны советской идеологией, и задали некий стандарт интеллектуального и творческого развития человека. Широта кругозора, смелость и нестандартность научного мышления, активная гражданская позиция составляли специфическую черту лучших советских ученых и изобретателей. Данный идеал широко пропагандировался, и смотрел на нас со страниц научнофантастических романов И. Ефремова, А. Беляева, К. Булычева, А. и Б. Стругацких и многих других писателей. В СССР существовал культ науки и знания: в различных теле- и радиопрограммах, в журналах и газетах для школьников «Пионер», «Костер», «Пионерская правда» постоянно проводились научнопознавательные викторины; на телеэкране огромную аудиторию собирала передача «Что? Где? Когда?»; большими тиражами выпускались журналы «Наука и жизнь», «Техника молодежи» и др.

Естественно, что современная концепция уровневого профессионального образования должна будет обеспечить историческую преемственность этих лучших советских традиций.

Отметим, что начиная с эпохи индустриализма, исследованию истории научного знания и технических изобретений придавалось большое значение. Ставилась прагматическая задача изучения опыта научных изобретений и открытий, чтобы учитывать ошибки прошлого и сделать научно-техническое творчество более эффективным [4]. Отношение к развитию науки в основном базировалась на ценностях эпохи Просвещения: культе научного знания («сциентизм») и восприятии истории человечества как торжества разума, науки и прогресса над невежеством и мракобесием. Широким массам населения прививались ценности научно-технической цивилизации и культура рационального мышления, а безудержная вера в прогресс нацеливала на конструктивное, созидательное отношение к будущему. На начальных этапах индустриализации одной из важных задач истории науки и техники было приобщение населения к ценностям научно-рационального мышления и техногенной цивилизации, поэтому место и роль техники часто романтизировалась и идеологизировалась. Так, в СССР широко было известно высказывание И.В. Сталина, что «техника во главе с людьми, овладевшими техникой, может и должна дать чудеса».

В государствах индустриальной эпохи изучение истории науки и техники имело еще и важный политико-идеологический аспект: изобретения и открытия национальных ученых всячески пропагандировались, а если какое-либо из них было спорным с точки зрения авторства или появлялось в нескольких странах одновременно (например, радио, или двигатель внутреннего сгорания), то провозглашался приоритет в их открытии отечественными учеными. Яркое выражение это нашло, например, в СССР 1940-60-х гг., когда из пропагандистских соображений пытались доказывать свое первенство во всем. Среди советских интеллектуалов ходила шутка, что рентгеновское излучение было открыто вовсе не выдающимся немецким ученым в конце XIX в., а намного раньше него русским царем Иваном Грозным, который говорил своим боярам, что «я вас насквозь вижу»! Для формирования патриотизма и национального самоуважения такой подход, может быть, и был отчасти полезен, но иногда в угоду пропаганде исторические факты явно подтасовывались.

В настоящее время преподавание истории науки и техники призвано решать несколько важных задач, стоящих перед обществом.

Bo-nервых, перед российской системой уровневого профессионального образования актуализировалась задача подготовки для промышленности инженерно-технических кадров (ИТР) мирового уровня, а без знания самых различных аспектов истории научнотехнического творчества высококвалифицированный специалист ИТР, способный к креативному мышлению и нестандартному подходу к задачам, немыслим.

Bo-вторых, усиливающаяся компьютеризация и информатизация всех сфер жизни современного общества задает совершенно новые требования к специалистам даже, казалось бы, сугубо гуманитарных специальностей. Так, например, значительная часть документоведов, юристов, менеджеров всех рангов сталкиваются в повседневной деятельности с электронным документооборотом [5], когда совершенно необходимыми становятся умения грамотного владения компьютером, создания и поддержки сайтов организации, защиты электронных баз документов от вирусов и кибершпионажа и т.д. И знание истории научно-технической мысли способно расширить необходимые компетенции гуманитария, развить его навыки в области компьютерных и информационных технологий и т.д.

B-mpeтьих, современная Россия столкнулась c обвальным падением научной культуры общества, и это выражается в достаточно широком распространении заблуждений, мифов и паранаучных представлений, в том числе и относительно тех или иных аспектов исторического развития. В современных СМИ 
много лженаучной и паранаучной информации: астрологических прогнозов, рассуждений о всевозможных пророчествах и предсказаниях, колдовстве и т.д. Определенной популярностью у населения пользуются квазирелигиозные верования, в основном восточного толка, основанные на идее «воздаяния» и «переселения душ». Данные идеи, естественно, играют свою роль в примирения человека с действительностью, и могут давать ему некую психологическую устойчивость в современной достаточно агрессивной и динамичной социальной среде. Но чаще всего они входят в противоречие с объективно-научным познанием мира: научное объяснение многих явлений заменяется использованием мифологизированным, научно-популярной терминологии [6, с. 30]. Падение научной культуры, возрождение веры в сверхъестественное, восприятие себя пассивным субъектом воздействия власти или мистических сил - это характерные черты мышления эпохи Средневековья, которые начинают стремительно воспроизводиться в нашей действительности.

Рассмотрим, какие основные проблемные, узловые моменты должна рассматривать «История науки и техники» при подготовке профессионалов различного уровня.

Bo-nервых, представляется важным ознакомление учащихся с крупными учеными и изобретателями, процессом их творчества, а также основным фактами и тенденциями развития научного знания и техники в различные эпохи. Особый интерес здесь представляют исследователи, чьи изобретения не были до конца реализованы, а вокруг них возник некий ореол таинственности: самый яркий пример здесь, пожалуй, Никола Тесла. Это формирует у учащихся способность оценивать альтернативные сценарии внедрения каких-либо научнотехнических инноваций и изобретений.

Bo-вторых, отдельное внимание уделить научным революциям, сменам научных парадигм, a также различным концепциям научнотехнической революции (НТР), научнотехнического прогресса (НТП), «информационного общества» как важнейшим вехам научно-технического развития человечества, целостное и системное осмысление которых закладывает культуру научного мышления специалиста в любой сфере деятельности.

B-третьих, проводить сравнительноисторический анализ отечественных и зарубежных научных открытий и достижений для адекватного представления об уровне исследований и развенчания деструктивных мифов относительно «отсталости России от цивилизованного мира».
$B$-четвертых, комплексно изучить ряд фундаментальных проблем истории отечественной науки и промышленности: например, почему часто отечественная промышленность не успевала за внедрением новейших достижений инженерной мысли и ноухау (такое было и в царской России, и в СССР)? Какие социально-политические и экономические институты и организации создавались для решения данных задач? Как можно оценить их эффективность и возможность применения данного опыта к современным условиям? Эти, и ряд других подобных вопросов, представляют интерес как для будущих инженеров, так и для управленцев в различных отраслях хозяйства.

$B$-nяmыx, уделить место рассмотрению актуальных проблем современной науки, созданию адекватных представлений о еe достижениях и перспективах исследований. Например, сейчас ставится вопрос об изучении феноменов, которые еще лет 30-40 назад казались лженаукой и суевериями: например, фиксация биополя человека как специфической совокупности его электромагнитных излучений и др. Надо сказать, что в СМИ при описании современных научных открытий и изобретений часто бывают ложные сенсации, и встречаются случаи, когда исследователь, чтобы привлечь внимание к проекту и обеспечить финансирование, в рекламных целях выдает планируемые результаты за уже достигнутые. Естественно, что учащимся необходимо иметь системные представления об основных направлениях развития науки и техники в современном мире.

$B$-иестыx, интересной междисциплинарной проблемой является восприимчивость общества к модернизационным процессам, весь комплекс взаимосвязи между менталитетом общества и развитием в нем ценностей научно-технической цивилизации, способности к внедрению в экономику и повседневный быт техники и технологий. Так, уже стал классическим пример «японского экономического чуда»: как страна, где во многом доминировали ценностномировоззренческие установки, свойственные феодализму, смогла в короткий срок догнать, а затем и перегнать ведущие западные страны по уровню развития техники и технологий? И при этом многие черты традиционного сознания японцев органически вписались в динамичную модернизационную модель развития.

Естественно, что как для исследователей, так и для учащихся представляет интерес комплекс вопросов, связанный со способностью российского общества к модернизации. Для создания эффективных институтов по ускорению научно-технического развития необходимо знать исторические особенности взаимодействия 
менталитета общества с процессами технологической и политической модернизации. Рассмотрим этот вопрос боле подробно.

Так, в дореволюционной России уровень научно-исследовательской мысли во многих направлениях науки был на уровне ведущих мировых школ. Д.И. Менделеев, А.С. Попов, А.М. Бутлеров, Н.И. Лобачевский, П.Н. Яблочков, И.М. Сеченов, В.М. Бехтерев, И.П. Павлов, И.И. Мечников и десятки других исследователей составляли цвет мировой науки, и, казалось бы, страна должна была успешно развиваться по пути модернизации, развития образования и промышленности. Но само общество того периода было явно не готово к серьезным модернизационным изменениям (как технологического, так и политического плана): низкий уровень общей грамотности населения (на начало XX в. - около $30 \%$, тогда как в ведущих странах Европы был 80-90\%); архаичные установки традиционалистского сознания; феодальные пережитки в обществе, например, сословное неравенство, выработавшее у значительной части бывших крепостных раболепное почитание к барину [7, с. 260] и безынициативность - все это было серьезным тормозом на пути проникновения в общество ценностей научно-технической цивилизации.

Играли свою роль и особенности существующих общественно-политических институтов [8, с. 41]. В России исторически государственная власть брала на себя функции проведения модернизаций «сверху», и практически все российские модернизации основывались не на развитии институтов гражданского самоуправления, а на подавлении личности государством, характерном для обществ «мобилизационного типа», и, по сути, создании модели «директивной» экономики. Можно согласиться с мнением Р. Пайпса, что в интересах национального могущества и престижа население побуждали образовываться, обогащаться и вырабатывать у себя государственное сознание. В то же самое время ожидали, что оно будет терпеть излишне опекающий его режим, который не признает для себя ни ограничений, ни норм и запрещает населению страхом сурового наказания открыто высказываться о возможности участия в политической жизни [9, с. 161]. Естественно, что данное противоречие не только вносило дисбаланс в общественно- политическое развитие страны, но и создавало препятствие для восприятия научно-технических достижений. Так, например, в 1905 г. в печати появилось две записки. Одна из них была подписана 198 инженерами, другая - группой фабрикантов и заводчиков Москвы. В этих документах отмечалось, что русская промышленность «Тяжело страдает от недостатков современного государственного строя, в котором народ разобщен с высоким носителем истинной власти и лишен возможности открыто высказываться, обсуждать назревшие вопросы...» [10, с. 370371].

Важное противоречие в менталитете, препятствующее модернизации и просвещению в дореволюционной России, отмечает также А.С. Ахиезер в своем фундаментальном труде «Россия. Критика исторического опыта». Исследователь полагает, что Россия не могла жить без просвещения, т.к. отстав от других, она могла потерять свою государственность и национальное существование. Но и просвещение несло собой для пораженного расколом общества смертельную опасность. Оно всем показало бы, что власть, государственность, царь, большое общество ничего общего не имеют с теми представлениями о социальной жизни, которые несло в себе синкретическое сознание, древний тотемизм во всех его модификациях. Для всех стало бы ясно, что царь вовсе не батюшка, а глава сословной системы и бюрократии, то это означало бы, что люди, опирающиеся на принципы древнего локализма, могли инверсионным образом отказаться от воспроизводства государственности, большого общества [11, с. 229-235].

Естественно, что эти и другие особенности ментальных установок российского общества и его политической структуры оказывали сдерживающее влияние на усвоение научнотехнических достижений, и все это находилось во взаимосвязи с запаздыванием промышленной революции. Очень наглядно данные тенденции демонстрируются на примере истории военной техники вооружений. Так, в начале XX в. русские конструкторы создавали образцы оружия, не уступающие европейским аналогам, но российская промышленность оказалась не в состоянии обеспечить ими армию в начальный период Первой мировой войны (хотя развитию оборонной промышленности отдавались приоритеты!). Вопиющий пример: подводный минный заградитель «Краб», созданный инженером М.П. Налетовым, строился 7 лет $(1908$ - 1915 гг.), тогда как в кайзеровской Германии, оценив идею создания боевых кораблей подобного класса, построили более 200 подводных минных заградителей в 1914-1918 гг. [12] (и это в условиях морской блокады и жесткого дефицита!)

Заключение. В преподавании студентам учебной дисциплины «История науки и техники» в уровневом профессиональном образовании у студентов должны вырабатываться умение применять продуктивные активные действия в достижении поставленных целей, что предполагает проблемно-дискуссионный 
характер обучения, развивающий мышление студентов. Это позволит вырабатывать у них знания, умения, владения, соответствующие профессиональным стандартам [13]. Акцент должен делаться на делается на ознакомлении с историческими фактами, их анализе и осмыслении, использовании междисциплинарных аналогий и связей, самостоятельном поиске решений учащимися. Предпочтение отдается самостоятельному поиску необходимой информации, обучению студентов методам работы с информацией, развитию у них профессиональной рефлексии и адаптации к изменяющимся условиям, умение демонстрировать собственное компетентное поведение.

В перспективе при изучении истории науки и техники материал и учебные задания следует давать более дифференцированно, в зависимости от уровня начальной подготовки студента и тех целей и задач, которые он ставит для себя в процессе учебы.

Исходя из опыта преподавания данной дисциплины, учащихся можно разделить на несколько групп:

Студенты (как бакалавры, так и магистранты), имеющие достаточно высокий уровень общей эрудиции, знакомые в целом с курсом истории (школьного или вузовского уровня) и некоторыми проблемными моментами истории науки и техники, интересующиеся различными вопросами научно-технического развития и читающие дополнительную литературу по ним. Таких студентов относительно немного, и, исходя из опыта преподавания автора данной работы, можно отметить тревожную тенденцию падения уровня эрудиции и начитанности у обучающихся, особенно заочной формы обучения. Для данных студентов очень интересен проблемный подход к обучению, изучение различных спорных и проблемных аспектов истории научного знания и технических изобретений, концептуальный анализ тенденций и исторических закономерностей научно-технического развития. Все это развивает культуру научного мышления будущего профессионала, формирует навыки нестандартного решения научных и производственно-практических проблем.

Студенты, мало интересующиеся проблематикой истории научно-технического развития, имеющие, как правило, средний уровень знаний по курсу истории. Обучающихся такого типа можно увлечь различными познавательными заданиями, интересными фактами из истории науки и техники, а специфика обучения будет направлена в основном на знакомство с самим материалом курса с использованием презентаций, видеоматериалов, активных и интерактивных форм обучения.

Студенты, имеющие низкую успеваемость и серьезные пробелы в знаниях истории: для них должен быть предусмотрен определенный минимум знаний по предмету, направленный на ликвидацию пробелов в знаниях и повышение общей эрудиции, знакомство хотя бы с основными положениями курса истории науки и техники [14, с. 10].

В заключение следует еще раз подчеркнуть важность знакомства студентов практически всех специальностей с основными тенденциями и закономерностями научно-технического развития России и мира.

\section{References:}

1. Osipova IV (2013) Modelirovanie processa didaktiko-tehnologicheskoj podgotovki pedagogov professional'nogo obuchenija // Vestnik Federal'nogo gosudarstvennogo obrazovatel'nogo uchrezhdenija vysshego professional'nogo obrazovanija Moskovskij gosudarstvennyj agroinzhenernyj universitet im. V.P. Gorjachkina. 2013. № 4. pp. 42-50.

2. Moskalenko MR (2015) Nekotorye voprosy prepodavanija istorii nauki $\mathrm{i}$ tehniki uchashhimsja inzhenerno-tehnicheskih special'nostej v Rossii // Theoretical \& Applied Science. 2015. № 4 (24). pp. 242-246.
3. (2015) History of science and technology. Available:

http://en.academic.ru/dic.nsf/enwiki/8564 (Accessed: 25.04.2015)

4. Vaganov A (2012) Nerazryvnost' i pravopreemstvo. Komu i zachem nuzhna segodnja istorija nauki i tehniki // Nezavisimaja gazeta. 22.02.2012. Available: http://www.ng.ru/science/2012-0222/9_pravopreemstvo.html

(Accessed: 12.03.2016).

5. Razinkov SL (2013) Uchebno-metodicheskoe posobie «Praktikum po ispol'zovaniju sistemy jelektronnogo dokumentooborota «Evfrat- 


\begin{tabular}{l|lrl|l|ll} 
& ISRA (India) & $=\mathbf{1 . 3 4 4}$ & SIS (USA) & $=\mathbf{0 . 9 1 2}$ & ICV (Poland) & $=\mathbf{6 . 6 3 0}$ \\
Impact Factor: & ISI (Dubai, UAE) $=\mathbf{0 . 8 2 9}$ & PUHL (Russia) $=\mathbf{0 . 1 7 9}$ & PIF (India) & $=\mathbf{1 . 9 4 0}$ \\
& GIF (Australia) & $\mathbf{0 . 5 6 4}$ & ESJI (KZ) & $=\mathbf{1 . 0 4 2}$ & IBI (India) & $=\mathbf{4 . 2 6 0}$ \\
& JIF & $\mathbf{1 . 5 0 0}$ & SJIF (Morocco) & $=\mathbf{2 . 0 3 1}$ & & \\
\hline
\end{tabular}

dokumentooborot» V.15» // Hroniki obyedinennogo fonda jelektronnyh resursov Nauka i obrazovanie. 2013. № 1 (44). pp. 31.

6. Doroshenko VA, Moskalenko MR (2014) Disciplina «Koncepcii sovremennogo estestvoznanija» V sovremennoj sisteme vysshego gumanitarnogo obrazovanija // Alma mater (Vestnik vysshej shkoly). 2014. № 5. pp. 28-32.

7. Dashkevich LA, Larionova MB, Nekljudov EG, Shalina IV (2015) Povsednevnaja zhizn' provincial'nogo imenija: dnevnik slugi ural'skih pomeshhikov Golubcovyh // "Quaestio Rossica». 2015. № 1. pp. 255-274.

8. Pajps R (1993) Rossija pri starom rezhime. Moscow: Nezavisimaja gazeta, 1993. 421 p.

9. (2012) Antropologija destruktivnosti: kollektivnaja monografija. Ekaterinburg: Ural'skij juridicheskij institut MVD Rossii, 2012. 214 p.

10. (1905) Vestnik Evropy. № 3.

11. Ahiezer AS (1997) Rossija: kritika istoricheskogo opyta: sociokul'turnaja dinamika
Rossii. V 2 t. T.1. Novosibirsk: Sibirskij hronograf, 1997. $800 \mathrm{p}$.

12. Zalesskij NA (2016) «Krab» - pervyj v mire podvodnyj minnyj zagraditel'. Available: http://romanbook.ru/book/5862549/?page (Accessed: 12.03.2016).

13. Ozhiganova MV (2013) Gosudarstvennaja politika $v$ sfere professional'nogo obrazovanija i professional'nye standarty // Sovremennye problemy prava i upravlenija. 3-ja Mezhdunarodnaja nauchnaja konferencija: sbornik dokladov v 2 chastjah. Redakcionnaja kollegija: Antonova N.N. (otvetstvennyj redaktor); Bogorodickij I.B. (glavnyj redaktor). 2013. pp. 76-81.

14. Moskalenko MR (2014) Osobennosti prepodavanija uchebnoj discipliny «Istorija nauki i tehniki» s primeneniem distancionnyh tehnologij obuchenija // Otkrytoe i distancionnoe obrazovanie. 2014. № 2 (54). pp. 5-10. 